ISSN 2179-345X

Licenciado sob uma Licença Creative Commons

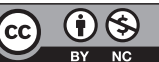

BY NC

\title{
O desenvolvimento sustentável como ótimo de Pareto na relação entre os princípios constitucionais ambientais e os princípios constitucionais econômicos ${ }^{1}$
}

\author{
Sustainable development as Pareto optimality in \\ the relationship between constitutional principles of \\ environment and constitutional principles of economy
}

\begin{abstract}
Felipe André Dani ${ }^{[a]}$, Álvaro Borges de Oliveira ${ }^{[b]}$, Débora Sabetzki Barros ${ }^{[c]}$
[a] Mestre em Ciências Jurídicas pela Universidade do Vale do Itajaí (Univali), área de concentração: Direito e Atividade Portuária, Transnacionalização, Bacharel em Direito pela Universidade de Passo Fundo (UPF), Passo Fundo, RS - Brasil, e-mail: felipeandre2000@hotmail.com

[b] Mestre em Direito, Graduado em Ciências da Computação, Doutor em Engenharia de Produção, professor do Mestrado no curso de Pós-Graduação em Ciência Jurídica da Universidade do Vale do Itajaí (UCPCJ/Univali), Camboriú, SC - Brasil, e-mail: alvaro@univali.br

[c] Graduanda do curso de Direito pela Universidade do Vale do Itajaí (Univali), Camboriú, SC - Brasil, e-mail: deborasabetzki@gmail.com
\end{abstract}

1 Neste artigo, procura-se cumprir as recomendações básicas constantes em Pasold (2007, p. 189-194). 


\section{Resumo}

Inicia-se o presente artigo fazendo referência aos princípios constitucionais e sua distinção em relação às regras. Dá-se especial atenção ao caráter de abstração dos princípios, o que não os torna imprecisos ou inaplicáveis, pelo contrário, os torna capaz de regular situações específicas e gerais do Direito. Na sequência, abordam-se princípios do Direito Ambiental e do Direito Econômico, com especial ênfase ao Princípio do Desenvolvimento Sustentável, princípio cunhado na Conferência de Estocolmo, em 1972, e difundido na Declaração do Rio (ECO 92). Tal princípio serve de fundamento do Direito Ambiental, tratando de equilibrar a relação entre desenvolvimento econômico e exploração ambiental, utilizado, portanto, como mediador dessa relação dicotômica. Ao fim, o ótimo de Pareto, ferramenta matemática, desenvolvida por Vilfredo Pareto, que traz uma visão de otimização dessa relação, entre princípios constitucionais ambientais e econômicos, serve para maximizar o desenvolvimento diminuindo a destruição ambiental, tudo sob o enfoque de um modelo neocapitalista, um modelo de desenvolvimento mais ambiental e preocupado com o bem-estar social.

Palavras-chave: Princípios constitucionais. Direito Ambiental. Desenvolvimento sustentável. Ótimo de Pareto. Neocapitalista.

\section{Abstract}

The present article is initiated making reference to the constitutional principles and its distinction in relation to the rules. it is paid special attention to the character of abstraction of the principles, which does not make them inaccurate or inapplicable, on the contrary, makes them capable of regulating specific and general situations of Law. In the sequence principles of the Enviromental law and the Economic law are approached, with special emphasis on the beginning of Sustainable Development, principle coined at the Conference of Estocolmo, in 1972, and at the Declaration of Rio (ECO 92). Such principle forms the basis of the Enviromental law, treating to balance the relation between economic development and ambient exploration, used, therefore, as mediating of this dichotomy relation. To the end, Pareto optimality, a mathematical tool developed by Vilfredo Pareto, that brings a vision of optimization of this relation, between Ambient and Economic principles constitutional, serves to maximize the development minimizing the ambient destruction, everything under the approach of a 
neo-capitalist model, a model of development more environmentally concerned and worried about the social welfare.

Keywords: Constitutional principles. Enviromental law. Sustainable development. Pareto optimality. Neocapitalism.

\section{Desenvolvimento}

O presente artigo trata dos princípios do ordenamento jurídico, sua distinção e aplicação, bem como sua diferença em comparação com as regras. Enfatizam-se os princípios constitucionais ambientais, em especial o princípio do desenvolvimento sustentável, além de tratar, com destaque, os princípios constitucionais do Direito Econômico. Princípios esses que, aparentemente, estão em oposição no ordenamento jurídico pátrio. Utilizou-se a conceituação e elementos do ótimo de Pareto na conciliação dos corolários do Direito Ambiental, com os do Direito Econômico, por meio do princípio do desenvolvimento sustentável; ferramenta útil na obtenção do máximo de desenvolvimento, por meio do mínimo de destruição do meio ambiente, aliado ao princípio da eficiência. Toda essa relação sob a abordagem de um novo modelo econômico, o neocapitalismo, modelo pós-capitalista, preocupado com o bem-estar social e com a manutenção e preservação ambiental.

\section{Os princípios constitucionais}

Os princípios não possuem um conceito estanque, definido e unitário. Como veremos, doutrinadores dizem que os princípios correspondem a normas de direito natural, verdades jurídicas universais e imutáveis. Inspiradas no sentido de equidade, Paulo Marcio Cruz (2006, p. 101) acentua sua destinação em "estabelecer os valores fundamentais 
para a interpretação, integração, conhecimento e aplicação do direito Positivo", portanto, são máximas que se alojam na Constituição, mas também podem estar inseridas nas regras do ordenamento positivo.

No decurso do tempo, os juristas foram evoluindo o seu pensamento e considerando os princípios como balizadores de condutas e como sinalizadores do Direito, passaram a ter juridicidade, independentemente da ideia de vagos ou coercitivamente desprovidos de poder impositivo. Tornaram-se fundamentais à ordem jurídica, pois sua importância está na sua impregnação em todo o sistema jurídico. Deixam de ser vagos no sentido de não terem conteúdo coercitivo e passam a ser observados como fundamento do ordenamento.

Os princípios, inicialmente, não possuíam o caráter de autênticas normas, em virtude de sua natureza transcendental, em razão de seu conteúdo e vagueza; esse último adjetivo advinha da falta de coerção, de imposição dos princípios, como também por serem dispositivos destituídos de sanção. Detectou-se um movimento com o objetivo de reconhecer a juridicidade aos princípios, passando a serem admitidos pelo Direito como imperativos.

Os princípios aparecem no sentido de fundamento, de base do sistema, em vez de figurarem no ordenamento jurídico apenas no sentido estrito de origem.

Conforme Miguel Reale (1986, p. 60), o conceito de princípio serve às ciências em geral como:

[...] verdades ou juízos fundamentais, que servem de alicerce ou de garantia de certeza a um conjunto de juízos, ordenados em um sistema de conceitos relativos a dada porção da realidade. Às vezes também se denominam princípios certas proposições que, apesar de não serem evidentes ou resultantes de evidências, são assumidas como fundantes de validez de um sistema particular de conhecimentos, como seus pressupostos necessários.

Ainda segundo Miguel Reale (2006, p. 304), princípios gerais de direito são "enunciações normativas de valor genérico, que condicionam 
e orientam a compreensão do ordenamento jurídico, quer para a sua aplicação e integração, quer para a elaboração de novas normas".

Paulo Bonavides (1994, p. 229) traz uma definição de princípios da Corte Constitucional italiana em 1956:

[...] deve-se considerar princípios do ordenamento jurídico, aquelas orientações e aquelas diretivas de caráter geral e fundamental que se possam deduzir da conexão sistemática, da coordenação e da íntima racionalidade das normas, que concorrem para formar assim, num dado momento histórico, o tecido do ordenamento jurídico.

Dessa forma, verifica-se que os princípios são como orientadores, balizadores das normas. Sua colaboração está em servir de fundamento para a criação das normas que irão compor o sistema normativo. Sua localização no ordenamento não se torna relevante, já que possuem uma superioridade em seu conteúdo, que os sobrepõe às regras normativas.

\section{Distinções entre princípios e regras}

Os princípios, bem como as regras, por possuírem ambos caráter normativo, são filiais de um mesmo gênero, a norma jurídica. Segundo Robert Alexy (1993, p. 83),

[...] tanto as regras como os princípios são normas porque ambos dizem o que deve ser. Ambos podem ser formulados com a ajuda das expressões deônticas básicas do mandamento, da permissão e da proibição. Os princípios, tal como as regras, são razões para juízos concretos de dever ser, ainda quando sejam razões de um tipo muito diferente. A distinção entre regras e princípios é, pois, uma distinção entre dois tipos de normas.

Os princípios possuem suas peculiares propriedades, diferenciando-os, por sua natureza qualitativa, dos demais preceitos jurídicos. A distinção está em tratar os princípios como uma primeira expressão dos valores fundamentais, que informam as demais normas. 
Observando-se uma hierarquia entre princípios e regras, notam-se os princípios acima das regras, e estes determinam integralmente qual há de ser a substância do ato, atuando como limitadores e embasadores na determinação das regras. Contudo, sob a ótica do pensamento de J. J. Gomes Canotilho (1993), os princípios seriam a base do ordenamento jurídico, sendo elevado, construído o Direito, a partir deles. Sob esse ponto de vista, os princípios se encontrariam na base do ordenamento e deles emergiriam as regras e todo o sistema jurídico, portanto, situando-se acima destes. Há, assim, diferentes formas de localizar os princípios sob diferentes enfoques, sendo localizados acima das regras, portanto, no ápice do ordenamento; ou sendo verificados na base do ordenamento, de onde emergiria este.

J. J. Gomes Canotilho (1993, p. 166) determina algumas características dos princípios, como o seu caráter fundamental, por serem fontes primeiras do Direito, e a proximidade dos princípios em relação à ideia básica de Direito, ainda que os princípios constituam a base, a ratio de regras jurídicas.

Cármen Lúcia Antunes Rocha (1994, p. 30), a respeito da procedência material dos princípios, pontua: "dotados de originalidade e superioridade material sobre todos os conteúdos que formam o ordenamento constitucional, os valores firmados pela sociedade são transformados pelo Direito em princípios".

Assim, verifica-se que os princípios emanam da sociedade, de ideais sociais, sendo observados e recepcionados pelo ordenamento jurídico, implícitos ou explícitos, norteiam a criação e a aplicação de regras a situações e a casos concretos.

Nesse sentido, Cármen Lúcia Antunes Rocha (1994, p. 23) prossegue afirmando que

os princípios constitucionais são os conteúdos intelectivos dos valores superiores adotados em dada sociedade política, materializados e formalizados juridicamente para produzir uma regulação política no Estado. Aqueles valores superiores encarnam-se nos princípios que formam a própria essência do sistema constitucional, dotando-o, 
assim, para cumprimento de suas funções, de normatividade jurídica. A sua opção ético-social antecede a sua caracterização normativo-jurídica. Quanto mais coerência guardar a principiologia constitucional com aquela opção, mais legítimo será o sistema jurídico e melhores condições de ter efetividade jurídica social.

Segundo a autora, os princípios nasceriam da sociedade e seriam recepcionados pelo Direito. Esse processo seria contínuo, e quanto mais o sistema jurídico for mutável, influenciado pelos princípios sócios, mais será a sua eficácia e melhor cumprirá o seu papel de normatizador de condutas e propulsor social.

Quanto à forma, os princípios são dotados de elevado grau de abstração, não significando, porém, impossibilidade de determinação. Isso não implica aos princípios a impossibilidade de regularem outras normas e até situações específicas, como decisões judiciais e atos administrativos, pois possuem densidade normativa. Segundo Fernando Muniz Santos (1995, p. 16), explicando a densidade normativa: "compreende-se a capacidade ou não duma determinada norma jurídica incidir num caso concreto de maneira direta, sem a necessidade da já aludida mediação concretizadora, por parte dos operadores jurídicos”. Essa abstração significa que os princípios muitas vezes não positivados no ordenamento incidem, regulam situações e o próprio ordenamento, portanto, a sua não positivação expressa; não quer dizer que não terá o princípio, força normativa ou reguladora, mas atuam em um plano onde sua concretude advém de ideologias, relações sociais, ética, e não apenas de sua positivação no sistema.

Essa abstração e abrangência não os torna sempre genéricos e imprecisos, ao contrário, possuem um significado determinado, passível de concretização por intermédio de mecanismos de aplicação desses preceitos jurídicos a casos concretos.

Os princípios, por possuírem uma estrutura maleável, aberta, podem incidir em diversos casos concretos e a sua aplicação é possível nas mais diferentes situações. Já as regras possuem uma estrutura pouco maleável, sendo mais rígidas, estabelecidas para incidir em determinadas situações. 
As regras aplicam integralmente os princípios, mas é impossível traduzi-los plenamente, pois as regras jurídicas nunca conseguem expressar e pormenorizar completamente os princípios de modo que se possa conseguir expressá-los inteiramente. Isso se dá pela riqueza de conteúdo dos princípios e por sua vagueza, deixando uma discricionariedade fundamental para regular a modernização de seus conceitos. A aplicação integral pelas regras dos princípios se dá pela sua observância. As regras devem sempre estar de acordo com os princípios, traduzindo-os, trazendo-os para o mundo da positivação. Isso quer dizer que o conteúdo dos princípios é tão amplo e tão disseminado, em diferentes situações e conteúdos, que se torna muito difícil uma regra material expressar em sua integralidade os princípios.

A interpretação e a aplicação das regras devem estar em conformidade com os princípios. Nenhum aspecto das regras deve escapar dos princípios, devendo ela basear-se por todos os ângulos nos princípios. Assim, as regras devem manifestar a aplicação integral dos princípios.

A característica normativa dos princípios é tratada por Norberto Bobbio (1990, p. 159), justificando: "a função para a qual são extraídos e empregados é a mesma cumprida por todas as normas, isto é, a função de regular um caso".

Além dessa função normativa, Edílson Pereira de Farias (1985, p. 41) determina uma função hermenêutica, servindo de limites à arbitrariedade:

os princípios são úteis em primeiro lugar para dirimir dúvidas interpretativas ao ajudar a esclarecer o sentido de determinada disposição de norma, contudo, a singularidade dos princípios no campo da interpretação é que eles servem de guia para a sua própria aplicação. Isso acontece porque os próprios princípios carecem de interpretação, e o agente jurídico terá que primeiramente interpretar os princípios vetores de sua interpretação.

Os princípios cumprem ainda a função de limitação da interpretação ao restringir a discricionariedade judicial. A referência obrigatória aos mesmos nos casos difíceis e duvidosos torna o processo de 
interpretação-aplicação do direito mais controlável e racional, porquanto evita que o operador jurídico invoque valores subjetivos não amparados de forma explícita ou implícita no ordenamento jurídico.

Dessa forma, há no ordenamento jurídico princípios interpretativos, que não possuem caráter normativo, auxiliando na interpretação, restrição desses princípios e do ordenamento.

A importância dos princípios jurídicos fundamentais é relatada por J. J. Gomes Canotilho (1993, p. 171-172):

importante fundamento para a interpretação, integração, conhecimento e aplicação do direito positivo. Mais rigorosamente, dir-se-á, em primeiro lugar, que os princípios têm uma função negativa particularmente relevante nos casos limites. A função negativa dos princípios é ainda importante noutros casos onde não está em causa a negação do Estado de Direito e da legalidade democrática, mas emerge com perigo o "excesso de poder" [...].

[...] eles fornecem sempre directivas materiais de interpretação das normas constitucionais. Mais do que isso: vinculam o legislador no momento legiferante, de modo a poder dizer-se ser a liberdade de conformação legislativa positiva e negativamente vinculada pelos princípios jurídicos gerais.

Os princípios têm múltiplos usos no ordenamento jurídico, servindo como fundamento do sistema para embasar decisões, interpretar e aplicar as normas jurídicas, bem como impedidores de abusos nessa aplicação das normas.

Quanto aos princípios constitucionais, são aqueles que impregnam o sistema constitucional, desempenhando papel fundamental como reflexos dos valores constitucionais em todo o ordenamento jurídico. Sob esse aspecto, para Luiz Henrique Cademartori (2001, p. 80),

os princípios constitucionais, explícitos e implícitos, desempenham um papel fundamental como reflexos normativos dos valores constitucionais conforme já se observou. Em outros termos, pode-se dizer 
que estes se traduzem juridicamente, desde a base do ordenamento jurídico, em princípios, nele explicitados ou não, tido como verdadeiros instrumentos de implementação e proteção de tais valores historicamente consagrados na maioria dos sistemas normativos ocidentais.

Quanto aos princípios constitucionais, utilizando uma divisão de Paulo Márcio Cruz (2006, p. 113), pode-se dividi-los em três tipos: os políticos ideológicos, os fundamentais gerais e os específicos.

Os princípios constitucionais político-ideológicos, segundo Paulo Márcio Cruz (2006, p. 113),

são aqueles que possuem dimensão axiológica fundamental. Pode-se dizer que funcionam como os "princípios dos princípios". Na Constituição da República Federativa do Brasil, como exemplos de princípios constitucionais político-ideológicos, podem-se citar aqueles inscritos no seu art. 4o, como o da independência nacional, o da prevalência dos direitos humanos, o da autodeterminação dos povos etc. Eles possuem o condão de orientar os demais princípios inscritos na Constituição e possuem um grau de concretude muito baixo.

Os princípios constitucionais político-ideológicos seriam a matéria-prima de todos os princípios, informando e norteando todos os demais, por isso seu grau de abstração é muito presente. Já os princípios constitucionais fundamentais, segundo Paulo Márcio Cruz (2006, p. 113), possuem um "alto grau de concretude e aplicabilidade", citando como exemplos os princípios do artigo $5^{\circ}$ da Constituição da República Federativa do Brasil de 1988.

Encerrando a classificação proposta por Paulo Márcio Cruz (2006, p. 113), os princípios constitucionais específicos "são aqueles que orientam uma determinada parte do Direito Constitucional. Na Constituição da República Federativa do Brasil, por exemplo, a maioria das matérias nela tratadas possuem princípios específicos".

Levando-se em conta essa divisão dos princípios constitucionais proposta por Paulo Márcio Cruz (2006), tem-se os princípios constitucionais ambientais, elencados no art. 225 da Constituição da República 
Federativa do Brasil de 1988, bem como os princípios da ordem econômica, informados no art. 170 da Carta Magna, como princípios constitucionais específicos, pois orientam uma determinada parte do Direito Constitucional e, consequentemente, determinam tanto o Direito Ambiental quanto o Direito Econômico.

No ordenamento jurídico, os princípios atuam desde a sua criação até a sua efetiva retirada do mundo abstrato e aplicação em cada caso concreto. São normas de otimização que buscam a excelência do sistema e uma resposta adequada aos conflitos sociais. São aspirações, ideais observados e desenvolvidos pela sociedade na busca da melhor solução para os conflitos, da melhor atuação do Direito ao se deparar com os casos concretos, trazidos ao mundo jurídico. Os princípios coordenam, organizam e impregnam todo o sistema, devendo ser observados na criação, desenvolvimento e aplicação de todo o ordenamento jurídico.

\section{Princípios constitucionais do Direito Ambiental}

Os princípios ambientais estão consagrados no texto constitucional brasileiro, de acordo com Nicolao Dino de Castro e Costa Neto (2003, p. 34):

a Constituição de 1988 agasalhou princípios que registram a preocupação da sociedade com a temática da proteção ambiental, expressando um avanço significativo nesse campo. Em vários momentos, com efeito, a Constituição Federal refere-se a princípios e normas princípios de conteúdo ambientalista.

Os princípios norteadores do Direito Ambiental estão basicamente elencados no art. 225 da Constituição da República Federativa do Brasil de 1988. Esses princípios são tratados por Celso Antônio Pacheco Fiorillo (2005, p. 28) como pedras basilares:

aludidos princípios constituem pedras basilares dos sistemas políticojurídicos dos Estados Civilizados, sendo adotados internacionalmente 
como fruto da necessidade de uma ecologia equilibrada e indicativos do caminho adequado para a proteção ambiental, em conformidade com a realidade social e os valores culturais de cada Estado.

De acordo com Paulo Affonso Leme Machado (2004, p. 43), os princípios que informam o Direito Ambiental são: princípio do acesso equitativo aos recursos naturais; princípios usuários-pagador e poluidorpagador; princípio da precaução; princípio da informação.

Já Cristiane Derani (2008, p. 136) aponta os princípios da cooperação, do poluidor-pagador e da precaução, como os pilares do Direito Ambiental.

Dentre os vários princípios do Direito Ambiental, como: princípio da cooperação, do poluidor pagador, da precaução e da prevenção, destaca-se o do desenvolvimento sustentável.

\section{Princípio do desenvolvimento sustentável}

É cunhado na Conferência de Estocolmo, em 1972, e permeia o Direito Ambiental desde então. Nasce da constatação de que os recursos naturais não são inesgotáveis, o que torna a sua exploração dependente de uma sustentabilidade.

De acordo com Clarissa Ferreira Macedo D'Isep (2009, p. 48), em referência ao nascimento desse princípio:

visualizando entre a defesa do meio ambiente e o desenvolvimento econômico, há uma dicotomia, na verdade, um antagonismo, criouse na Conferência de Estocolmo/72, nos princípios 5 e 8, a noção de "desenvolvimento sustentável" (ou "sustentado", ou ainda, "ecodesenvolvimento"), que prosperou, ecoando mais tarde em pelo menos onze dos vinte e sete Princípios da Declaração da Rio/92, em especial nos princípios 3 e 4, assim como no setor privado, mediante a sua implementação nos moldes de gerenciamento empresarial - a gestão ambiental. 
Antes da Declaração da Rio/92, esse princípio foi disseminado em 1983, na Assembleia das Nações Unidas, por meio do "Relatório Brundland", que leva esse nome, haja vista sua comissão elaboradora ser presidida pela ex-primeira ministra da Noruega. A essência desse princípio, à época, era o atendimento das necessidades e crescimento da sociedade sem o comprometimento dos recursos que atenderiam as gerações futuras.

O meio ambiente não pode sucumbir ou ser exterminado sob o pretexto de desenvolvimento. Segundo Celso Antônio Pacheco Fiorillo (2005, p. 29),

constata-se que os recursos ambientais não são inesgotáveis, tornandose inadmissível que as atividades econômicas desenvolvam-se alheias a esse fato. Busca-se com isso a coexistência harmônica entre economia e meio ambiente. Permite-se o desenvolvimento, mas de forma sustentável, planejada, para que os recursos hoje existentes não se esgotem ou tornem-se inócuos.

O objetivo do princípio do desenvolvimento sustentável é equilibrar o desenvolvimento econômico com a exploração ambiental, tentar otimizar o máximo de desenvolvimento, por meio do mínimo de sofrimento do meio ambiente, bem como garantir às gerações futuras, a existência de um meio ambiente capaz de acolher a todas as necessidades sociais.

De acordo com Cristiane Derani (2008, p. 113), "desenvolvimento sustentável implica, então, o ideal de um desenvolvimento harmônico da economia e ecologia que deve ser ajustado numa correlação de valores em que o máximo econômico reflita igualmente um máximo ecológico".

Discorrendo sobre a importância desse princípio, Nicolao Dino de Castro e Costa Neto (2003, p. 53) escreve:

tal princípio sintetiza um dos mais importantes pilares da temática jus-ambiental, compondo o núcleo essencial de todos os esforços empreendidos na construção de um quadro de desenvolvimento social menos adverso e de um cenário de distribuição de riquezas mais equânime. Numa visão eco-integradora, trata-se de estabelecer um 
liame entre o direito ao desenvolvimento, em todas as suas dimensões (humana, física econômica, política, cultural, social), e o direito a um ambiente sadio, edificando condições para que a humanidade possa projetar o seu amanhã.

Sobre a manutenção do meio ambiente para as gerações futuras, discorre Celso Antonio Pacheco Fiorillo (2005, p. 29):

dessa forma, o princípio do desenvolvimento sustentável tem por conteúdo a manutenção das bases vitais da produção e reprodução do homem e de suas atividades, garantindo igualmente uma relação satisfatória entre os homens e destes com o seu ambiente, para que as futuras gerações também tenham oportunidade de desfrutar os mesmos recursos que temos hoje a nossa disposição.

Além desse conceito de manutenção como forma de garantir as necessidades das presentes e futuras gerações, indicando uma continuidade que se sobrepõe às gerações presentes, preocupando-se com as futuras, traz Clarissa Ferreira Macedo D’Isep (2009, p. 50) a característica primordial do desenvolvimento sustentável:

a característica do ecodesenvolvimento é a busca contínua e efetiva de conciliação entre o desenvolvimento, a preservação ecológica e a qualidade de vida do homem. É de suma importância que se atente para a idéia de continuidade implícita na noção de desenvolvimento sustentável.

Além dessa ideia de continuidade e tentativa de eternização do meio ambiente, tidos como objetivos do princípio do desenvolvimento sustentável, esse mesmo princípio traz a ideia de meio ambiente finito, segundo Nicolau Dino de Castro e Costa Neto (2003, p. 59):

tal conceito traz em si o reconhecimento de que tais recursos naturais não são inesgotáveis. Ao mesmo tempo, expressa a compreensão de que não pode haver desenvolvimento pleno se os caminhos trilhados para sua consecução desprezarem um sistema de exploração racional e equilibrada do meio ambiente. 
Essa finitude do meio ambiente e dos recursos naturais faz com que o desenvolvimento econômico observe a conservação e manutenção do meio ambiente, e essa relação tem como princípio regulador o desenvolvimento sustentável.

A interligação entre ordem econômica e meio ambiente é tratada por Fernanda de Salles Cavedon (2003, p. 57):

os recursos naturais são bens econômicos, e a proteção legal do Meio Ambiente requer interferências na Ordem Econômica, principalmente na Propriedade Privada. Portanto, Ordem Econômica e Meio Ambiente estão interligados, e seu tratamento jurídico não pode dar-se de forma dissociada.

Essa interligação também é observada por Cristiane Derani (2008, p. 112):

quando se usa a expressão "desenvolvimento sustentável", tem-se em mente a expansão da atividade econômica vinculada a uma sustentabilidade tanto econômica quanto ecológica. Os criadores dessa expressão partem da constatação de que os recursos naturais são esgotáveis. Por outro lado, apóiam-se no postulado de que crescimento constante da economia é necessário para expandir-se o bem-estar pelo mundo.

O princípio do desenvolvimento sustentável está presente na Constituição da República Federativa do Brasil de 1988 também no artigo 170, sendo fundamental para a Ordem Econômica Nacional.

\section{Princípios constitucionais do direito econômico}

O artigo 170 da Constituição da República Federativa do Brasil de 1988 traça uma estrutura geral do ordenamento jurídico econômico. Direito econômico é a regulamentação da política econômica, como meio de dirigir, indicar, regular as práticas econômicas, sempre buscando compatibilizar conflitos dentro de uma orientação macroeconômica. 
Nesse sentido, Cristiane Derani (2008, p. 38), citando Habermas, afirma o seguinte:

tendo em mente esta capacidade de ajuste do direito, afirma Habermas que a relação entre direito e economia é comunicativa e livre em relação a instituições e parâmetros preexistentes, podendo tirar até conseqüências anarquistas, no sentido de possibilitar mudanças das instituições com vistas a garantir uma verdadeira relação entre Estado e Direito e garantia de efetiva liberdade.

Segundo Ivo Dantas (1999, p. 58-59),

até a Revolução de 1930, a preocupação do constitucionalismo brasileiro para com o econômico e social, era mínima, sendo de anotarse que a elevação dessas matérias ao nível de normas constitucionais ocorreu a partir do texto de 1934, cujas raízes embora pouco referidas, encontram-se na reforma sofrida pela Constituição de 1981, no ano de 1926, através da qual se permite ao Congresso Nacional legislar sobre o Comércio exterior e interior, podendo autorizar as limitações exigidas pelo bem público.

A Constituição da República dos Estados Unidos do Brasil de 1934 interviu no domínio econômico ao dispor em seu artigo $131^{2}$ que a propriedade deveria ser de brasileiros natos.

Já a Constituição dos Estados Unidos do Brasil de 1937 trouxe consigo uma virtude ao consagrar a expressão "ordem econômica", embora em seu conteúdo (artigos 137 a 139) tenha indicado normas referentes ao Direito do Trabalho e à Previdência Social (DANTAS, 1999, p. 61).

2 Art. 131: É vedada a propriedade de empresas jornalísticas, políticas ou noticiosas a sociedades anônimas por ações ao portador e a estrangeiros. Estes e as pessoas jurídicas não podem ser acionistas das sociedades anônimas proprietárias de tais empresas. A responsabilidade principal e de orientação intelectual ou administrativa da imprensa política ou noticiosa só por brasileiros natos pode ser exercida. A lei orgânica de imprensa estabelecerá regras relativas ao trabalho dos redatores, operários e demais empregados, assegurando-lhes estabilidade, férias e aposentadoria. 
$\mathrm{Na}$ Constituição dos Estados Unidos do Brasil de 1946 a ordem econômica e social é tratada no título $\mathrm{V}$, dispondo o artigo $147^{3}$ sobre o uso da propriedade. A Constituição da República Federativa do Brasil de 1967 determina no Título III, artigo 157, ${ }^{4}$ os princípios da ordem econômica.

A ordem econômica e financeira está inserida na Constituição da República Federativa do Brasil de 1988, no Título VII, estatuindo preceitos reguladores dos direitos e deveres dos agentes econômicos, sendo princípios constitucionais.

De acordo com Cristiane Derani (2008, p. 236), sobre a finalidade da ordem econômica existente no artigo 170 da Constituição da República Federativa do Brasil:

conforme dispõe o caput do art. 170, a finalidade da ordem econômica estaria em assegurar a todos existência digna, conforme os ditames da justiça social. Estes preceitos são a razão de todo texto sob o título da ordem econômica e financeira da Constituição Federal.

No Título VII existem os preceitos constitucionais que disciplinam, juridicamente, a macroeconomia, tendo como objetivo sustentar de forma jurídico-constitucional a ordem econômica, assegurando elementos de ordem monetária, tributária e financeira. O conteúdo permeia os princípios da atividade econômica, as políticas urbanas, agrícola e fundiária e o sistema financeiro nacional.

Segundo Isabel Vaz (1993, p. 319), interpretando a Constituição da República Federativa do Brasil de 1988, quanto à diminuição do papel do Estado nas atividades econômicas:

3 Art. 147: O uso da propriedade será condicionado ao bem estar social. A lei poderá com observância ao disposto no art. 141, §16, promover a justa distribuição da propriedade, com igual oportunidade para todos.

4 Art. 157: A Ordem Econômica tem por fim realizar a justiça social, com base nos seguintes princípios: I - liberdade de iniciativa; II - valorização do trabalho como condição da dignidade humana; III função social da Propriedade; IV - harmonia e solidariedade entre os fatores de produção; V desenvolvimento econômico; VI - repressão ao abuso do poder econômico, caracterizado pelo domínio dos mercados, a eliminação da concorrência e o aumento arbitrário dos lucros. 
a leitura da Constituição Brasileira em vigor revela tanto uma diminuição do papel do Estado nas atividades econômicas quanto a instigação do particular para que participe, de modo mais ativo, na realização dos objetivos da ordem econômica e financeira e da ordem social.

A atividade econômica está ligada à apropriação privada dos meios de produção e à livre iniciativa, as quais consubstanciam na ordem econômica capitalista, sendo alguns dos seus princípios gerais: propriedade privada, função social da propriedade, princípio da livre concorrência, princípio da defesa do consumidor, princípio da redução das desigualdades regionais e sociais, princípio da busca do pleno emprego, princípio da defesa do meio ambiente, entre outros.

Segundo o artigo $170^{5}$ da Constituição da República Federativa do Brasil de 1988, a ordem econômica tem como fundamentos a valorização do trabalho humano e da livre iniciativa, ambas ideias do modelo econômico capitalista, sendo as bases de sustentação da ordem econômica mundial.

A valorização do trabalho humano é a principal fonte de riqueza das nações; a valorização do trabalho, permitindo uma justa remuneração, condizente com as necessidades do trabalhador e de sua família, iria de encontro a uma ordem social mais justa, evitando o aviltamento da mão de obra e a consequente divisão de riquezas.

De acordo com Ivo Dantas (1999, p. 68),

5 Art. 170: A ordem econômica, fundada na valorização do trabalho humano e na livre iniciativa, tem por fim assegurar a todos existência digna, conforme os ditames da justiça social, observados os seguintes princípios: I - soberania nacional; II - propriedade privada; III - função social da propriedade; IV - livre concorrência; V - defesa do consumidor; VI - defesa do meio ambiente, inclusive mediante tratamento diferenciado conforme o impacto ambiental dos produtos e serviços e de seus processos de elaboração e prestação; VII - redução das desigualdades regionais e sociais; VIII - busca do pleno emprego; IX - tratamento favorecido para as empresas de pequeno porte constituídas sob as leis brasileiras e que tenham sua sede e administração no País. Parágrafo único. É assegurado a todos o livre exercício de qualquer atividade econômica, independente de autorização de órgãos públicos, salvo nos casos previstos em lei. 
o trabalho a que se refere a Constituição, não é o trabalho escravo, mas sim, o trabalho livre, e para tanto a própria Lei procura assegurar-lhe esta aludida valorização, quando, no Artigo $7^{\circ}$ estabelece "direitos dos trabalhadores urbanos e rurais" que visem à "melhoria de sua condição social”.

Além do trabalho humano, o meio ambiente, atualmente, tem grande importância como fonte de riqueza das nações. O acervo florestal natural passou a ter valorização econômica com a degradação acentuada e extinção de algumas espécies presentes no meio ambiente mundial. Seu reconhecimento fez com que países com vasta imensidão florestal e hídrica tivessem relevância mundial. Isso faz com que normas de Direito Econômico e Ambiental tenham interligações, pois a política econômica abraça também questões de caráter ambiental.

Segundo Cristiane Derani (2008, p. 48), "são indissociáveis os fundamentos econômicos de uma política ambiental conseqüente e exeqüível. E uma política econômica conseqüente não ignora a necessidade de uma política de proteção dos recursos naturais".

De acordo com Cristiane Derani (2008, p. 51), essa interligação também leva em conta a natureza como recurso, como fornecedora de matéria-prima, e acrescenta que:

sobre a natureza como fonte de reprodução econômica concentra-se a grande maioria das preocupações, aí residindo as contribuições da economia ambiental ou economia de recursos. A economia ambiental focaliza o papel da natureza como fornecedora de matéria-prima ou como receptora de materiais danosos.

Passando a tratar mais especificamente do princípio geral da ordem econômica, que é a defesa do meio ambiente, para Ivo Dantas (1999, p. 75-76) é outra inovação do texto constitucional, visto que os seus precedentes não continham nenhuma regra sobre meio ambiente. A CRFB/88 não se contentou em enumerá-lo como um dos princípios da atividade econômica, mas lhe dedicou todo o Capítulo VI do Título VIII (artigo 225, 
incisos e parágrafos), afirmando, no caput do referido artigo, que todos têm direito ao meio ambiente ecologicamente equilibrado, bem de uso comum do povo e essencial à sadia qualidade de vida, impondo-se ao Poder Público e à coletividade o dever de defendê-lo e preservá-lo para as presentes e futuras gerações.

Evidente se torna a inter-relação entre os princípios constitucionais ambientais e os princípios constitucionais da ordem econômica; seu relacionamento e interdependência, cada vez mais, salientam e priorizam a defesa ambiental.

De acordo com Eros Roberto Grau (1981, p. 56), ao tratar de justiça social e desenvolvimento econômico:

o elemento fundamental na noção de justiça social, enquanto fim da ordem econômica, está centralizado na pressuposição de uma melhoria da repartição do produzido como consequência da sua realização. Por certo que, por isso mesmo, a justiça social compreende bem-estar geral, da comunidade - mesmo porque a disseminação do bem-estar pela comunidade é resultante daquela melhoria.

Continua Eros Roberto Grau (1991, p. 57):

nada menos exato, pois a compatibilização entre justiça social e desenvolvimento envolve precisamente a harmonização da eficiência com os princípios da justiça. Evidente que todo o Direito está voltado para esta harmonização, mas fora de dúvida também que é no âmbito do direito Econômico que ela se opera de modo pronunciado e marcante.

Fazendo uma releitura de justiça social para desenvolvimento sustentável, englobando não só a distribuição de riquezas, mas sim um cuidado com o meio ambiente no desenvolvimento econômico sustentável, temos a evolução do conceito operado por Eros Roberto Grau para justiça social, muito mais amplo e abrangente, englobando também o meio ambiente.

Por meio do ótimo de Pareto se obtém um ideal de harmonização e otimização entre o desenvolvimento sustentável como um princípio 
ambiental e o desenvolvimento econômico, como uma necessidade do modelo econômico mundial.

\section{Ótimo de Pareto}

A eficiência, ou ótimo de Pareto, é um conceito econômico desenvolvido por Vilfredo Pareto. Segundo esse conceito, uma situação econômica seria ótima quando não puder mais ser melhorada, ou quando não se puder melhorar um dos fatores sem o detrimento de outro fator participante.

A tentativa de conciliar o desenvolvimento com a preservação do meio ambiente a princípio parece impossível, pois trata-se de, aparentemente, dois institutos conflitantes.

Segundo Cristiane Derani (2008, p. 100), essa relação durante a Revolução Industrial tinha a subserviência do meio ambiente:

o início do desenvolvimento da produção industrial estava atrelado ao fato da existência de recursos adequados. Aço, carvão, ferro, alimento representaram condições decisivas para a Revolução Industrial, apesar da não-monetarização do valor da existência de tais recursos. Cidades cresceram e minguaram a medida que os recursos naturais que sustentavam o seu desenvolvimento desapareciam.

O princípio do desenvolvimento sustentável tenta atribuir o máximo de desenvolvimento com o mínimo de destruição da natureza. Sob essa ótica, aplicando o ótimo de Pareto, teríamos uma otimização da utilização dos recursos naturais, direcionado ao máximo de desenvolvimento econômico possível.

Sobre essa relação escreve Cristiane Derani (2008, p. 102):

a economia parte da dominação e transformação da natureza e é por isso dependente da disponibilidade de recursos naturais. Esta dominação/transformação está direcionada à obtenção de valor, que se materializa em forma de dinheiro, riqueza criada. Como equilibrar riqueza 
coletiva existente e esgotável com riqueza individual e criável é a grande questão para a conciliação entre economia e ecologia. Não há verdadeiro progresso com deterioração da qualidade de vida, e será ilusório qualquer desenvolvimento à custa da degradação ecológica.

Ainda segundo Cristiane Derani (2008, p. 113):

desenvolvimento sustentável é a tradução do ótimo de Pareto a ser encontrado entre desenvolvimento econômico e a proteção dos recursos naturais. Sua lógica abstrata pode ser aplicada no seguinte parágrafo: O crescimento econômico precisa ser avaliado criticamente com relação aos critérios gerais ligados ao bem-estar, uma vez que não se pode deixar de observar especialmente os efeitos ambientais do crescimento como medida para o aumento do bem-estar.

Tentativa de otimizar essa relação pode ser observada quanto ao princípio do poluidor pagador, haja vista que quanto mais poluição causar maior será a multa aplicada. Segundo Cristiane Derani (2008, p. 115):

a imposição de um custo ao causador do dano não significa necessariamente que o dano será eliminado. O princípio do poluidor-pagador não está em eliminar o efeito negativo, ele está inscrito na lógica do ótimo de Pareto, exigindo uma ponderação, uma espécie de avaliação do custo-benefício econômico (financeiro).

Isso não quer dizer que o princípio do poluidor pagador é o direito de poluir, pelo contrário, caso a destruição ambiental já tenha ocorrido, sendo impossível retornar ao status quo, a reprimenda financeira aparece como única alternativa de sanção.

Utilizando o princípio do desenvolvimento sustentável na relação entre desenvolvimento e preservação, sendo observado o ótimo de Pareto, de acordo com Cristiane Derani (2008, p. 115):

a economia de mercado atinge seu grau ótimo quando realiza uma satisfatória relação entre o uso de um recurso natural e sua conservação, 
encontrando um preço que permite a utilização do bem ao mesmo tempo que conserva. Em outras palavras, a relação uso e não uso deve atingir um estágio ótimo que permita a continuação desta prática econômica, ou seja, a sustentabilidade do desenvolvimento.

Sendo assim, o desenvolvimento sustentável é o ótimo de Pareto, pois a sustentabilidade do desenvolvimento econômico, por meio da utilização da natureza como fonte de matéria-prima, levará à preservação do meio ambiente, preservação essa que vai de encontro ao conceito do princípio de desenvolvimento sustentável.

Cristiane Derani (2008, p. 116) aborda o princípio da eficiência nos seguintes termos: "na teoria neoclássica é previsto o uso ótimo dos recursos (inclusive os naturais) - princípio da eficiência. Porém, esta otimização é impossível, quando não se pode determinar pela preferência individual o valor dos recursos naturais".

O ótimo de Pareto não significa o nível zero de destruição do meio ambiente para o desenvolvimento econômico, deve-se observar uma relação de custo-benefício, em que o custo do desenvolvimento econômico não pode ser superior à destruição do meio ambiente.

Analisando o sistema econômico mundial, sob a ótica da preservação ambiental, Clarissa Ferreira Macedo D’Isep (2009, p. 48) sinaliza que a poluição maior é a pobreza:

assegurar o meio ambiente ecologicamente equilibrado é, inexoravelmente, promover a sadia qualidade de vida. Entretanto, dentro da nossa atual concepção de qualidade de vida, está englobado o bemestar econômico, pois a sociedade que vivemos hoje é tipicamente uma sociedade de consumo. Isso nos permite afirmar que, aos olhos dessa sociedade, a poluição maior é a pobreza.

Esse viés, que utiliza a poluição como mensuração de riqueza e pobreza, advém do modelo econômico neocapitalista, que procura, por meio da preservação ambiental e da erradicação da pobreza, a geração e acumulação de capitais. Uma ótica contraposta ao capitalismo clássico, 
que possuía, em suas bases, a utilização descontrolada do meio ambiente, causando a sua destruição e extinção, para o bem-estar social de uma seleta camada social, detentora dos meios de produção e concentradora das riquezas.

Essa nova concepção econômica observou a possibilidade de geração de riquezas por meio da preservação ambiental. Exemplo disso são os créditos de carbono, que utilizam as ideias do ótimo de Pareto, do princípio do desenvolvimento sustentável, para criar mecanismos de retirada da atmosfera terrestre do elemento carbono, por meio da implantação, nos países subdesenvolvidos, de projetos de desenvolvimento econômico sustentáveis, ou seja, desenvolvimento econômico e preservação ambiental.

\section{Modelo econômico neocapitalista}

A dinâmica social permite a evolução constante dos modelos econômicos utilizados; muitas vezes, esses modelos extinguem-se abruptamente, como foi o caso do comunismo e do socialismo na antiga União Soviética, porém, outras tantas vezes, se modernizam e sofrem mutações dentro de um sistema aberto.

Segundo Celso Antonio Pacheco Fiorillo (2005, p. 30),

sabemos que o liberalismo tornou-se um sistema inoperante diante do fenômeno da revolução das massas. Em face da transformação sociopolítica-econômica-tecnológica, percebeu-se a necessidade de um modelo estatal intervencionista, com a finalidade de reequilibrar o mercado econômico.

Com isso, a noção e o conceito de desenvolvimento, formados num Estado de concepção liberal, alteraram-se, porquanto não mais encontravam guarida na sociedade moderna. Passou-se a reclamar um papel ativo do Estado no socorro dos valores ambientais, conferindo outra noção ao conceito de desenvolvimento. A proteção do meio ambiente e o fenômeno desenvolvimentista (sendo composto pela livre iniciativa) 
passaram a fazer parte de um objetivo comum, pressupondo a convergência de objetivos das políticas de desenvolvimento econômico, social, cultural e proteção ambiental.

Ainda sobre a evolução do sistema capitalista, Fernando Bastos de Ávila (1963, p. 37) diz:

o capitalismo evoluiu, entretanto para um novo sistema que se caracteriza por um esforço tendente a corrigir os erros econômicos, sociais e políticos do capitalismo, que se desvincula de suas premissas filosóficas, mas que, entretanto ainda atribui a última instância - no processo sócio-econômico - ao capital. Tal sistema pode chamar-se Neo-Capitalismo.

Fernando Bastos de Ávila (1963, p. 39) assevera que esse novo modelo econômico é mais atento à distribuição de riquezas e à preservação ambiental e:

o Neo-Capitalismo das grandes potências, enfim, adota atitudes novas com relação aos povos mais atrasados e dispõe-se a cooperar com eles, compreendendo inclusive que é esta a única maneira de afastá-los da órbita comunista.

De acordo com Paulo Márcio Cruz e Osvaldo Ferreira de Melo (2011), sobre a superação do Estado constitucional moderno, lançam a progressão para um modelo econômico mais solidário na distribuição, pois "sem democracia solidária e sem a democratização do capital, com distribuição de riqueza, não há como organizar um novo Poder Público, que seja fruto da superação da Soberania endógena do Estado Constitucional Moderno".

A racionalidade, o melhor aproveitamento, sob a ótica do ótimo de Pareto e de um desenvolvimento sustentável, também estão presentes no neocapitalismo. Segundo Paulo Márcio Cruz (2009, p. 223): 
a racionalidade dos agentes individuais, famílias e empresas, que buscam a máxima vantagem nas transações econômicas que fazem, assegura o uso mais eficiente e econômico dos escassos recursos disponíveis atualmente no mercado e na economia.

O neocapitalismo é o termo utilizado para designar a evolução do capitalismo, sendo o seu surgimento pós-Segunda Guerra Mundial, com a ascensão das sociedades reconstruídas, caracterizando-se pela correção dos excessos do capitalismo, mediante a aplicação de conceitos, visando ao bem-estar social.

Nota-se a evolução para um modelo econômico mais preocupado com a distribuição de riquezas e com a preservação do meio ambiente. Esse novo modelo capitalista, denominado neocapitalismo, encontrou a fórmula de gerar riquezas e lucro com a preservação ambiental e obteve, por meio de regulamentação e da criação de ferramentas, a capacidade de manter seu crescimento econômico embasado na relação desenvolvimento econômico e preservação ambiental, sem, contudo, olvidar princípios capitalistas, como a propriedade privada.

\section{Considerações finais}

O artigo tratou da relação conflitante entre economia e ambiente, ou seja, o desenvolvimento econômico e a preservação ambiental. Essa relação se dá referendando os princípios constitucionais, normas abstratas e genéricas que estão inseridas em todo o ordenamento jurídico, e que atuam sobre todos os mecanismos e formas de expressão deste, por meio de normas e regras; em destaque os princípios constitucionais ambientais, basicamente elencados no artigo 225 da Constituição da República Federativa do Brasil e também os princípios ambientais econômicos, dispostos no artigo 170 da Carta Magna de 1988.

Utilizou-se como mediador para essa relação, aparentemente oposta, o princípio do desenvolvimento sustentável e, de forma indireta, 
o princípio da eficiência. Demonstrou-se que o ótimo de Pareto, ou seja, a melhor combinação de fatores, é, sem dúvida, o desenvolvimento econômico sustentável, com especial atenção à preservação ambiental. Toda a relação conflitante é apresentada levando-se em conta um novo modelo econômico mundial, o neocapitalismo, muito mais preocupado com o meio ambiente e com o ser humano. Portanto, a relação colidente entre os princípios ambientais e econômicos pode ser mitigada se observado o princípio do desenvolvimento sustentável.

\section{Referências}

ALEXY, R. Teoria de los derechos fundamentales. Madrid: Centro de Estudios Constitucionales, 1993.

ÁVILA, F. B. de. Neo-capitalismo, socialismo, solidarismo. Rio de Janeiro: Livraria Agir, 1963.

BOBBIO, N. Teoria do ordenamento jurídico. São Paulo: Polis; Brasília: Universidade de Brasília, 1990.

BONAVIDES, P. Curso de direito constitucional. 5. ed. São Paulo: Malheiros, 1994.

CADEMARTORI, L. H. Discricionariedade administrativa - no estado constitucional de direito. Curitiba: Juruá, 2001.

CANOTILHO, J. J. G. Direito constitucional. 6. ed. Coimbra: Livraria Almedina, 1993.

COStA NETO, N. D. de C. e. Proteção jurídica do meio ambiente: I florestas. Belo Horizonte: Del Rey, 2003.

CAVEDON, F. de S. Função social e ambiental da propriedade. Florianópolis: Visualbooks, 2003.

CRUZ, P. M. Fundamentos do direito constitucional. Curitiba: Juruá, 2006. 
CRUZ, P. M. Política, poder, ideologia e estado contemporâneo. Curitiba: Juruá, 2009.

CRUZ, P. M.; MELO, O. F. de. Soberania e superação do estado constitucional. Disponível em: <http://bdjur.stj.gov.br/xmlui/bitstream/handle/2011/18428/ Soberania_e_Supera\%C3\%A7\%C3\%A3o_do_Estado.pdf?sequence=2>. Acesso em: 26 jun. 2011.

DANTAS, I. Direito constitucional econômico: globalização e constitucionalismo. Curitiba: Juruá, 1999.

DERANI, C. Direito ambiental econômico. São Paulo: Saraiva, 2008.

D’ISEP, C. F. M. Direito ambiental econômico e a ISO 14000. São Paulo: Revista dos Tribunais, 2009.

GRAU, E. R. Elementos de direito econômico. São Paulo: Revista dos Tribunais, 1981.

FARIAS, E. P. de. Colisão de direitos: a honra, a intimidade, a vida privada e a imagem versus a liberdade de expressão e informação. Porto Alegre: Sérgio Antonio Fabris, 1985.

FIORILLO, C. A. P. Curso de direito ambiental brasileiro. São Paulo: Saraiva, 2005.

GRAU, E. R. Elementos de direito econômico. São Paulo: Revista dos Tribunais, 1981.

MACHADO, P. A. L. Direito ambiental brasileiro. São Paulo: Malheiros, 2004.

PASOLD, C. L. Prática da pesquisa jurídica e metodologia da pesquisa jurídica. Florianópolis: OAB/SC, 2007.

REALE, M. Filosofia do direito. 11. ed. São Paulo: Saraiva, 1986.

REALE, M. Lições preliminares de direito. São Paulo: Saraiva, 2006. 
ROCHA, C. L. A. Princípios constitucionais da administração pública. Belo Horizonte: Del Rey, 1994.

SANTOS, F. M. Os princípios e as regras constitucionais enquanto normas jurídicas. Curitiba: UFPR, 1995.

VAZ, I. Direito econômico da propriedade. Rio de Janeiro: Forense, 1993.

Recebido: 01/03/2011

Received: 03/01/2011

Aprovado: 05/04/2011

Approved: 04/05/2011 